\title{
Attention Deficit Hyperactivity Disorder (ADHD) and Offending Behaviour- Case Report
}

\author{
Jibowu Olubokun ${ }^{1,2, *}$
}

${ }^{1}$ Specialist Child and Adolescent Mental Health Services, South West Yorkshire Partnership Foundation NHS Trust, Calderdale CAMHS, 51 Northgate, Halifax, HX1 IUB, UK

${ }^{2}$ Serco Health, The Office Campus, Red Hall Court, Wakefield, WF1 2UY, UK

\begin{abstract}
The association between Attention Deficit Hyperactivity Disorder (ADHD) and Offending behaviour is well documented in Literature. The DSM IV and the NICE Clinical guidelines state that Hyperactivity, Impulsiveness and poor concentration are the core features of this condition. Attention Deficit Hyperactivity Disorder can be seen as a Neurodevelopmental disorder and a spectrum disorder.

In this case report the discontinuation of pharmacological treatment with Modified release preparation of Methyl phenidate Hydrochloride led to an escalation of offending behaviour within a few weeks which resulted in an admission into a Secure Children's facility in Leeds West Yorkshire and Subsequent 'Electronic tagging' in a 15 year old.

Some young persons with ADHD can present with 'complex needs' and Health care professionals, Drug workers and other staff as well as Forensic Physicians working within the Custodial and Forensic settings would need to be sensitive and responsive to their needs in order to ensure the continuity of treatment for as long as is practicable and achievable even whilst in custody.

The importance of multidisciplinary and multiagency working with a 'joined up' approach so as to maximise out come is highlighted.
\end{abstract}

Keywords: Adhd, offending, behaviour, crime, youth, Ritalin.

\section{INTRODUCTION}

Attention Deficit Hyperactivity disorder can be regarded as a Neurodevelopmental disorder with the core features of Inattention, Hyperactivity and Impulsivity (Diagnostic and Statistical Manual, DSM IV, 1994. National Institute for Health and Clinical Excellence, NICE Guidelines, 2008). It is Classified as a Hyperkinetic disorder in the International Classification for Diseases, (ICD 10, WHO, 1992). It is a common mental health condition in Children and Young Adults with a Worldwide prevalence of $5 \%$ (Polanczyk 2007) It is also associated with significant Co Morbidity or Co - occurring disorders, Functional Impairments and Family Burden (Coghill, Soutullo, d'Aubuisson, Preuss, Lindback, Silverberg and Buitelaar, 2008) There is often associated conduct disorder and oppositional defiant behaviour of up to 40$50 \%$ (McBurnett and Pfiffer 2009) in some studies.

Quite often young persons and some young adults seen in custody and in secure Forensic settings and indeed within the criminal justice system have a history of treatment for ADHD and the associated high risk taking behaviours for example verbal and physical

*Address correspondence to this author at the Specialist Child and Adolescent Mental Health Services, South West Yorkshire Partnership Foundation NHS Trust, Calderdale CAMHS, 51 Northgate, Halifax, HX1 IUB, UK; Tel: +441422 261 300; Fax: 01422261 350; E-mail: Jibsolubok@aol.com aggression with damage to property, varying degrees of physical assault including Grievous Bodily harm and Actual Bodily harm, Robbery and Burglary, aggravated burglary, Fire setting, breach of the peace and multiple substance use and other drug related offences.

There is evidence from literature confirming association between ADHD and offending behaviour (Lambert 1989; Manuzza, Klein, Konig and Gianpino. 1989; Satterfield, Swanson and Schell 1994) and also that youths with ADHD are more likely to be arrested and to begin criminal activity at a much younger age (Retz, Retz- Junginger, Hengesch, Schneider, Thome, Pajonk, SalahiDufam. 2004; Young, Adamou, Bolea, Mullet, Pitt's, Thome and Asherton, 2011) When clinical assessment using the DSM IV criteria are conducted in prison and custody settings rates of in mates with persistent ADHD symptoms are around 45 $\%$. for youth offenders (Rosler, Retz, RetzJunginger, Hengesh, Schneider, Suppriam and Schwitzgebal 2004; Young S, Gudjonsson GH, Misc P, Collins P, Carter P, Redfern J, Goodwin, 2010) falling to about $30 \%$ for male adults and $10 \%$ for female adults (Rosler, Retz, Yaqoobi, Burg, Retz Juginger 2009) 
A more recent study shows that ADHD drug treatment reduces criminal behaviour in adults.

This case study involves a 15 year old young person who was on drug treatment for ADHD with the modified release preparation of Methyl Phenidate hydrochloride in the community in addition to other Multidisciplinary support. His Medication was stopped because of his persistent cannabis use. His offending behaviour then subsequently became escalated which led to him being admitted into a Children's secure Unit and was then 'electronically Tagged ' to facilitate close monitoring because of the high risk he poses to himself and others in the community.

\section{CASE REPORT}

CGS is a 15 year old boy who was referred to the Specialist Tier 3 Community child and Adolescent Mental Health service in Calderdale, Halifax, West Yorkshire by his General Practitioner.

He was referred following his discharge from a Children's secure facility, in Leeds where he was on admission for 2 months. He was diagnosed with Attention Deficit Hyperactivity Disorder in 2011.

His past Medical History shows that there were no physical health concerns on completion of the Health needs assessment. He has no history of a heart condition, epilepsy, liver or kidney condition and no history of Motor tic disorder or Tourrette's. His Immunisation was discussed and the opportunity for him to receive protection against Hepatitis $A$ and $B$. He consented and this was initiated

His Pregnancy and Antenatal history as well as his developmental history were essentially normal.

In terms of his Family and Social history. He currently lives at home with mum and Dad. He stated that he uses alcohol regularly and that he smokes cigarettes about 15 per day. He has used Cannabis regularly in the past.

Mum works as an Administartive officer with a local safe guarding Children's Team and Dad works as a manager in a Food Processing factory.

He currently attends WM high school and is in year 10 but prior to this he attended SB high school but was excluded many times because of disruptive, maladaptive and high risk behaviours before his final exclusion and subsequent transfer to the secure Unit.
He was excluded because he was not staying at school and persistently wandering the streets during school hours, shoplifting, Engaging in Robbery, smoking Cannabis, getting into fights with strangers and causing damage to property.

He was in education while at the secure unit and was also getting Psychoeducation and had 1; 1 sessions with his drug worker.

CGS was having regular support by the Youth Offending team and has an allocated Key worker who sees him everyday for the past 2 years. There were no issues with Fire setting. CGS is currently electronically tagged for the past 6 months. He stated this was essentially to keep him safe at home and to be able to monitor him closely in the community. He has broken his curfew many times and is always breaching the terms of his Court Order. He has been to court several times all related to shoplifting, breach of the peace and breaching of court Order.

His Mental State was settled during interview. He maintained good eye contact and rapport. He was not restless nor agitated. His speech was coherent, intelligible and relevant to the questions asked. There was no hyperactivity or unsual or bizarre experiences. No suicidal thoughts or ideas and was quite appropriate throughout the interview.

On Physical Examination; His blood pressure was $113 / 56 \mathrm{mmHg}$. Pulse 79 per minute, regular with good volume. Height was $162 \mathrm{~cm}$ and Weight $56.8 \mathrm{Kg}$. His Chest was Clear and Abdomen normal.

\section{PSYCHOMETRIC MEASUREMENTS}

His Conner's Parent and Teacher Rating Scales showed highly significant scores on all the domains of functioning as at the time. These were in the domains of Cognitive /Inattention, Oppositional Behaviour, Emotional and Peer Relationship and the Overall ADHD Index.

He had a speech and language Therapy Assessment using the British Picture Vocabulary scales (BPVS) and subtests of the Clinical Evaluation of language Fundamentals (CELF4). This showed that he has broadly age equivalent communication skills but that his vocabulary was slightly reduced for his age and that he displayed good social communication skills. It recommended that staff working with him would need to explain any new or more complex vocabulary. 
His most recent assessment using the Mental Health Screening Questionnaire for intervention in Adolescents (SQIFA) developed by the Youth Justice Board did not raise any new concerns.

In terms of his drug treatment he was initially commenced on low dose immediate release Methyl phenidate Hydrochloride which was gradually increased to Equasym XL 40mg once daily his current dose

\section{DISCUSSION}

In this case report the young person was started on pharmacological treatment for ADHD at the age of 12 . He was commenced on low dose immediate release preparation of Methylphenidate hydrochloride at $10 \mathrm{mg}$ per oral daily. His baseline investigations Full Blood Count, Liver function tests, Electrolytes and urea, Thyroid function Tests and Electrocardiogram were all within normal limits. His weight was above the $50^{\text {th }}$ centile and Height above the $9^{\text {th }}$ centile for his age and sex. His oral dose was gradually increased initially and then later switched to a modified release preparation at $40 \mathrm{mg}$ per oral daily. Some of the advantages of the modified release preparation are the prolonged duration of action of up to $8-12 \mathrm{hrs}$ on the average and single daily dosage which therefore obviates the need for an extra dose of medication at Lunch time at school. Having to take medication during the lunch hour at school is often associated with stigma and inconveniences for the child and as well as the Teacher whereas without this requirement adherence to medication is likely to be improved.

Treatment with Ritalin was discontinued because of his frequent use of Cannabis and Alcohol and in order to minimise the risks of adverse and toxic effects associated with Methylphenidate hydrochloride. This is a controlled drug and is fraught with its own risks especially the risks of cardiovascular events, exacerbation of motor tics and Tourrette's among others, in addition to the less troublesome side effects of Headaches, abdominal pains, difficulties with sleep and reduced appetite which may lead to weight loss.

It is significant that his medication was stopped in September 2012 and within a 3 month period afterwards he was admitted into the Secure Unit because of recurrent offending behaviour mainly Shoplifting and Robbery which may be in part to fund his drug habbit.
A recent Swedish study has shown that Adults with Attention Deficit Hyperactivity disorder are less likely to commit criminal offences when taking medication (Torjesen 2012) The reverse of the statement can also be said to be true from this case study.

This highlights the importance of the need to continue medication for as long as is practicable especially in this vulnerable group. In addition to the repeated offending whilst he was off treatment, he was also frequently breaking the curfew imposed on him and breaching the terms of his court order which eventually led to him being Electronically tagged so as to be able to monitor him more closely in the community. It is important to point out that a 15 year old with ADHD who wears an Electronic Tag is in a different 'league'. What this means is that children and young persons with attention deficit hyperactivity disorder especially those at the more severe end of the spectrum often have 'Complex needs' in terms of the challenges that they present to the services. The approach to their management and Care plan of essence have to be multidisciplinary and multiagency. This will involve 'joint working' with a range of services to include, Education, Child and Adolescent Mental Health services, social services, Probation, Law enforcement Agents and the Police, Youth Offending Teams, Drugs and Alcohol services, Courts and the Criminal Justice System. This is in order to deliver a top level and expedient clinical care and optimise outcomes. A Knowledge of the local referral pathway for ADHD will also be useful to health care practitioners and Forensic physicians as this will facilitate access to the local resources available.

One of the main objectives of this case report is to sensitise as well as create an awareness for Forensic Physicians, Health Care Professionals, Drug workers and other staff working in the custodial environment. and forensic Settings of the need to continue drug treatment for ADHD for as long as possible while the young person is going through the Criminal Justice system in order to optimise the outcome.

\section{REFERENCES}

American Psychiatric Association. Diagnostic and Statistical Manual. $19944^{\text {th }}$ ed. New York, APA.

Coghill D, Soutullo C, d'Aubuisson C, Preuss U, Lindback T, Silverberg M, Buitelaar J, 2008. Impact of Attention Deficit Hyperactivity disorder on patient and family: result from a European survey. Child Adolescent Psychiatry and Mental Health $2 ; 31$

http://dx.doi.org/10.1186/1753-2000-2-31 
Lambert N M. 1989 Adolescent outcomes for hyperactive children. Perspectives on general and specific pattern of childhood risk for adolescent educational, social and mental health problem. American Psychologist, 43: 786-799 http://dx.doi.org/10.1037/0003-066X.43.10.786

Manuzza S, Klein RG, Konig PH, Gianpino TL. 1989. Hyperactive boys almost grown up. Criminality and its relationship to psychiatric status. Archives of General Psychiatry. 46: 1073 1079

http://dx.doi.org/10.1001/archpsyc.1989.01810120015004

McBurnett K and Pfiffer LJ. 2009. The treatment of aggressive ADHD in children and adolescents, conceptualisation and treatment of co morbid behaviour disorders. Post grad Med. 121 96): 158-65

National Institute for Health and Clinical Excellence: Quick Reference Guide, 2008 - Attention Deficit Hyperactivity disorder. Nice Clinical Guideline 72. London.

Polanczyk G. 2007. The World wide prevalence of Attention Deficit Hyperactivity Disorder: A systematic review and metaregression analysis. Am J Psychiatry; 164: 942-8 http://dx.doi.org/10.1176/appi.ajp.164.6.942

Retz W. Retz- Junginger P, Hengesch G, Schneider M, Thome J, Pajonk FG, Salahi- Dufam A. 2004. Psychometric and psychopathological characterisation of young male prison inmates with and without attention deficit/hyperactivity disorder. European Archives of Psychiatry and Clinical Neurosciences. 254: 201-208 http://dx.doi.org/10.1007/s00406-004-0470-9

Rosler M, Retz W, Retz- Junginger P, Hengesh G, Schneider M, Suppriam T, Schwitzgebal P. 2004. Prevalence of attention deficit - hyperactivity disorder (ADHD) and co morbid disorder in young male prison inmates. European Archives of Psychiatry and clinical Neuroscience. ; 254; 365 -371 http://dx.doi.org/10.1007/s00406-004-0516-z

Rosler M, Retz W, Yaqoobi K, Burg E, Retz Juginger P. 2009 Attention Deficit Hyperactivity disiorder in Female offenders; prevalence, psychiatric co morbidity and psychosocial implicatios. European Archives of Psychiatry and Clinical Neuro science. 259: $98-105$ http://dx.doi.org/10.1007/s00406-008-0841-8

Satterfield J H, Swanson J, Schell AM and Lee F. 1994. Prediction of antisocial behaviour in attention deficit hyperactivity disorder boys from aggression/defiance scores. Journal of American Psychiatry, 33:185-190

Torjesen I, 2012. Drug treatment reduces criminal behaviour in adults with ADHD British Medical Journal 345e 7915 http://dx.doi.org/10.1136/bmj.e7915

World Health Organisation. The International Classification of Diseases. 1992. (ICD 10) $10^{\text {th ed }}$. Geneva. WHO.

Young S, Adamou M, Bolea B, Mullet U, Pitt's M, Thome J and Asherton $P, 2011$. The Identification and management of ADHD offenders within the criminal Justice system: A consensus statement from the UK adult ADHD Network and Criminal Justice Agencies. BMC Psychiatry. 11:32 http://dx.doi.org/10.1186/1471-244X-11-32

Young S, Gudjonsson GH, Misc P, Collins P, Carter P, Redfern J, and Goodwin E. 2010. The prevalence of ADHD symptoms among youths in a secure facility: The consistency and accuracy of self and informant report ratings. Journal of Forensic Psychiatry and Psychology. 21 (2) 238 -246 http://dx.doi.org/10.1080/14789940903311566

\section{DOI: http://dx.doi.org/10.6000/1929-4409.2014.03.01}

(c) 2014 Jibowu Olubokun; Licensee Lifescience Global.

This is an open access article licensed under the terms of the Creative Commons Attribution Non-Commercial License (http://creativecommons.org/licenses/by-nc/3.0/) which permits unrestricted, non-commercial use, distribution and reproduction in any medium, provided the work is properly cited. 